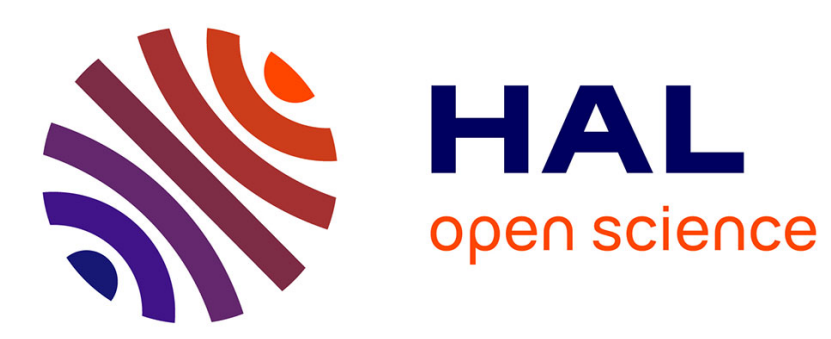

\title{
Immunopurification of Intact Endosomal Compartments for Lipid Analyses in Arabidopsis
}

Yoko Ito, Magali S. Grison, Nicolas Esnay, Laetitia Fouillen, Yohann Boutté

\section{To cite this version:}

Yoko Ito, Magali S. Grison, Nicolas Esnay, Laetitia Fouillen, Yohann Boutté. Immunopurification of Intact Endosomal Compartments for Lipid Analyses in Arabidopsis. Plant Endosomes, pp 119-141, 2020, 978-1-0716-0766-4. 10.1007/978-1-0716-0767-1_11. hal-02992204

\section{HAL Id: hal-02992204 \\ https://hal.science/hal-02992204}

Submitted on 6 Nov 2020

HAL is a multi-disciplinary open access archive for the deposit and dissemination of scientific research documents, whether they are published or not. The documents may come from teaching and research institutions in France or abroad, or from public or private research centers.
L'archive ouverte pluridisciplinaire HAL, est destinée au dépôt et à la diffusion de documents scientifiques de niveau recherche, publiés ou non, émanant des établissements d'enseignement et de recherche français ou étrangers, des laboratoires publics ou privés. 


\section{Metadata of the chapter that will be visualized online}

\begin{tabular}{|c|c|c|}
\hline Chapter Title & \multicolumn{2}{|c|}{$\begin{array}{l}\text { Immunopurification of Intact Endosomal Compartments for Lipid Analyses } \\
\text { in Arabidopsis }\end{array}$} \\
\hline Copyright Year & \multicolumn{2}{|l|}{2020} \\
\hline Copyright Holder & \multicolumn{2}{|c|}{ Springer Science+Business Media, LLC, part of Springer Nature } \\
\hline \multirow{6}{*}{ Author } & Family Name & Ito \\
\hline & Particle & \\
\hline & Given Name & Yoko \\
\hline & Suffix & \\
\hline & Organization & $\begin{array}{l}\text { Laboratoire de Biogenèse Membranaire, UMR 5200, CNRS, } \\
\text { Université de Bordeaux }\end{array}$ \\
\hline & Address & Villenave d'Ornon, France \\
\hline \multirow[t]{7}{*}{ Corresponding Author } & Family Name & Grison \\
\hline & Particle & \\
\hline & Given Name & Magali \\
\hline & Suffix & \\
\hline & Organization & $\begin{array}{l}\text { Laboratoire de Biogenèse Membranaire, UMR 5200, CNRS, } \\
\text { Université de Bordeaux }\end{array}$ \\
\hline & Address & Villenave d'Ornon, France \\
\hline & Email & magali.grison@u-bordeaux.fr \\
\hline \multirow[t]{9}{*}{ Author } & Family Name & Esnay \\
\hline & Particle & \\
\hline & Given Name & Nicolas \\
\hline & Suffix & \\
\hline & Organization & $\begin{array}{l}\text { Laboratoire de Biogenèse Membranaire, UMR 5200, CNRS, } \\
\text { Université de Bordeaux }\end{array}$ \\
\hline & Address & Villenave d'Ornon, France \\
\hline & Division & Department of Biological Sciences, BioDiscovery Institute \\
\hline & Organization & University of North Texas \\
\hline & Address & Denton, TX, USA \\
\hline \multirow[t]{8}{*}{ Author } & Family Name & Fouillen \\
\hline & Particle & \\
\hline & Given Name & Laetitia \\
\hline & Suffix & \\
\hline & Organization & $\begin{array}{l}\text { Laboratoire de Biogenèse Membranaire, UMR 5200, CNRS, } \\
\text { Université de Bordeaux }\end{array}$ \\
\hline & Address & Villenave d'Ornon, France \\
\hline & Division & MetaboHub-Metabolome Facility of Bordeaux \\
\hline & Organization & \\
\hline
\end{tabular}




\section{Author's Proof}

\section{Functional Genomics Center}

Address Bordeaux, France

\begin{tabular}{lll}
\hline Corresponding Author & Family Name & Boutté \\
& Particle & \\
& Given Name & Yohann \\
& Suffix & \\
& Organization & Laboratoire de Biogenèse Membranaire, UMR 5200, CNRS, \\
& Université de Bordeaux \\
& Address & Villenave d'Ornon, France \\
& Email & yohann.boutte@u-bordeaux.fr \\
\hline
\end{tabular}

Abstract

Endosomes play a major role in various cellular processes including cell-cell signaling, development and cellular responses to environment. Endosomes are dynamically organized into a complex set of endomembrane compartments themselves subcompartmentalized in distinct pools or subpopulations. It is increasingly evident that endosomes dynamics and maturation is driven by local modification of lipid composition. The diversity of membrane lipids is impressive and their homeostasis often involves crosstalk between distinct lipid classes. Hence, biochemical characterization of endosomal membrane lipidome would clarify the maturation steps of endocytic routes. Immunopurification of intact endomembrane compartments has been employed in recent years to isolate early and late endosomal compartments and can even be used to separate subpopulations of early endosomes. In this section, we will describe the immunoprecipitation protocol to isolate endosomes with the aim to analyze the lipid content. We will detail a procedure to identify the total fatty acid and sterol content of isolated endosomes as a first line of lipid identification. Advantages and limitations of the method will be discussed as well as potential pitfalls and critical steps.

Keywords Organelles - Immunopurification - Golgi - Endosomes - Lipids - Fatty acids - 


\title{
Author's Proof
}

\section{Chapter 11 .}

\section{Immunopurification of Intact Endosomal Compartments for Lipid Analyses in Arabidopsis}

\author{
Yoko Ito, Magali Grison, Nicolas Esnay, Laetitia Fouillen, \\ and Yohann Boutté
}

\begin{abstract}
Endosomes play a major role in various cellular processes including cell-cell signaling, development and 7 cellular responses to environment. Endosomes are dynamically organized into a complex set of endomem- 8 brane compartments themselves subcompartmentalized in distinct pools or subpopulations. It is increas- 9 ingly evident that endosomes dynamics and maturation is driven by local modification of lipid composition. 10 The diversity of membrane lipids is impressive and their homeostasis often involves crosstalk between 11 distinct lipid classes. Hence, biochemical characterization of endosomal membrane lipidome would clarify 12 the maturation steps of endocytic routes. Immunopurification of intact endomembrane compartments has 13 been employed in recent years to isolate early and late endosomal compartments and can even be used to 14 separate subpopulations of early endosomes. In this section, we will describe the immunoprecipitation 15 protocol to isolate endosomes with the aim to analyze the lipid content. We will detail a procedure to 16 identify the total fatty acid and sterol content of isolated endosomes as a first line of lipid identification. 17 Advantages and limitations of the method will be discussed as well as potential pitfalls and critical steps. 18

Key words Organelles, Immunopurification, Golgi, Endosomes, Lipids, Fatty acids, Mass spectro- 19 metry, Plants

1 Introduction

The endosomal network is a highly coordinated set of endomem- 23 brane compartments which host materials coming from early endo- 24 cytic events at the plasma membrane through early endosomes 25 (EEs), which are then dispatched over recycling pathways back to 26 the plasma membrane or degradation pathways through late endo- 27 somes (LEs). However, plants have no EEs as described in animals, 28 and endocytic vesicles converge directly to the trans-Golgi Net- 29 work (TGN) where the endocytic tracer FM4-64 was found to 30 accumulate relatively fast (couple of minutes) during endocytosis 31
\end{abstract}

Yoko Ito and Magali Grison contributed equally to this work.

Marisa S. Otegui (ed.), Plant Endosomes: Methods and Protocols, Methods in Molecular Biology, vol. 2177,

https://doi.org/10.1007/978-1-0716-0767-1_11, (C) Springer Science+Business Media, LLC, part of Springer Nature 2020 


\section{Author's Proof}

Yoko Ito et al.

before reaching LEs [1-3]. TGN is a tubulovesicular membrane network that originates from the trans-most cisternae of the Golgi apparatus, acting as a main central station in endosomal trafficking. In plants, the TGN can undergo homotypic fusion and can associate transiently with Golgi apparatus, similarly to what is found for EEs and TGN in mammalian cells $[2,4]$. Moreover, plant TGN can detach from the Golgi apparatus to form a highly dynamic Golgiindependent structure (Golgi-Independent TGN; GI-TGN) $[2,4]$. From electron microscopy (EM) ultrastructural studies, at least three populations of TGN-associated vesicles could be identified, the secretory vesicles (TGN-SVs) that do not bear any apparent coat and which size vary between $\sim 50$ and $100 \mathrm{~nm}$ in diameter, the clathrin vesicles (TGN-CCVs) that possess a clathrin coat and measure $\sim 35 \mathrm{~nm}$, and the COPIb-type of vesicles that carry a COPI coat and measure $\sim 45 \mathrm{~nm}$ in diameter [5-7]. From confocal colocalization studies we know that TGN-SVs are marked with the V-ATPase VHA-al, the syntaxin proteins SYP61 and SYP43 and the protein ECHIDNA while TGN-CCVs are marked with the RAB-GTPase RAB-A2a [1, 6, 8-14]. It is not completely clear if TGN-SVs and TGN-CCVs can both contain endocytic materials; however, EM and live-cell observations suggest that endocytosis tracers are found at GI-TGN within a few minutes after endocytosis, and both the CCV marker clathrin and the SV marker VHA-al localize on GI-TGN more than on Golgi-associated TGN [2, 3, $6]$. Hence, to completely understand the time frame and maturation steps of endocytic routes, there is a stumbling block to overcome. Cell biology approaches indicate that TGN and endosomes are made of subpopulations that might not have the same lipid and protein content, reflecting the maturation and dynamics of these endomembrane compartments. This view should now be scaled up with multidisciplinary approaches to understand the chemistry and biochemistry of membranes including proteins and lipids.

In recent years, the development of methods allowing for the purification of organelles using different specific baits opened the door to the biochemical characterization of distinct endocytic compartments. Isolation of intracellular organelles was done previously by classical density gradient centrifugation but these methods have several limitations due to similar densities of distinct intracellular compartments and the diversity of small compartments found in one fraction. Localization of organelle proteins by isotope tagging (LOPIT) has been used on iodixanol gradients to group proteins using principal component analysis and allowed to clearly separate Golgi proteins from endoplasmic reticulum (ER) proteins [15]. The Golgi apparatus was also isolated by combination of density gradient and the surface charge separation technique called free-flow electrophoresis (FFE) [16]. Very recently, a subtle combination of LOPIT and FFE was used to determine the proteins and glycan content of Golgi cisternae from the ER to the trans-most 
side of the Golgi apparatus [17]. However, these methods do not 80 allow for separation of subpopulations of endosomes, and compart- 81 ments such as TGN-SVs and TGN-CCVs would be hard to isolate 82 independently. Nonetheless, EM studies have identified the pres- 83 ence of proteins to specific subpopulations of TGN or endosomes 84 $[6,9,13]$. Hence, these hallmarks can be used as tags to isolate 85 compartments in a target specific way with high specificity using 86 immunoaffinity approaches. The first study used SYP61 fused to 87 GFP as a bait for TGN using anti-GFP antibodies coupled to 88 agarose-beads as affinity ligand [18]. This method was also adapted 89 to magnetic beads using VHA-al fused to YFP as TGN bait and 90 coupled to LOPIT technique [19]. Immunoisolation was further 91 used on a range of markers belonging to the Wave collection [20] 92 labeling the Golgi, TGN, EEs, or LEs [21]. 93

Immunoisolation procedures have proved to be very useful to 94 determine the proteome of intact and full Golgi cisternae, TGN, 95 EEs, or LEs and get a clearer view of the identity of these compart- 96 ments. It has also become increasingly evident that lipids are key 97 determinants of membrane identity, sorting mechanisms and mat- 98 uration processes. A well-known process accompanying endocyto- 99 sis and maturation of endosomes in mammalian cells is the 100 conversion of phosphoinositides (PIPs), which are negatively 101 charged phosphorylated forms of phospholipids [22]. This change 102 in lipid composition drives the recruitment of distinct RAB 103 GTPases and defines a new identity to the compartment. Another 104 example of lipid involvement in membrane maturation is the accu- 105 mulation of phosphatidic acid (PA), a lipid which favor vesicle 106 fission, at the neck of constricted COPI vesicles through the action 107 of phospholipase D (PLD) that converts phosphatidylcholine 108 (PC) into PA [23]. In plants, immunoisolation of distinct subdo- 109 mains of TGN using magnetic beads coupled to anti-GFP antibo- 110 dies has successfully reached the separation of TGN-associated SVs 111 (using SYP61-CFP as a bait) and TGN-associated CCVs (using 112 RAB-A2a-YFP as a bait) to analyze lipid composition [14]. Strik- 113 ingly, an enrichment of $\alpha$-hydroxylated very-long-chain fatty acids 114 (hVLCFAs), a specific signature of sphingolipids (SLs), was 115 observed together with an enrichment of sterols at SVs as compared 116 to CCVs [14]. Characterizing the complete fatty acids (FAs) and 117 sterols profile of immunoisolated compartments by gas chromatog- 118 raphy-mass spectrometry (GC-MS) is the first step to the in-depth 119 characterization of lipid composition. Certainly, lipidomic profiling 120 using liquid chromatography mass spectrometry (LC-MS) would 121 definitely be the most powerful approach to identify several classes 122 and species of lipids in one sample. However, the diversity of lipids 123 is estimated to include more than forty thousand molecular species 124 as referenced in LIPID MAPS online database (https://www. 125 lipidmaps.org/). A general definition of lipids would be a hydro- 126 phobic or amphiphilic molecular assembly soluble in organic 127 


\section{Author's Proof}

Yoko Ito et al.

solvents. This definition includes a huge structural diversity ranging from but not limited to (1) glycerolipids composed from a glycerol backbone on which one, two or three FAs are esterified, (2) glycerophospholipids composed from a glycerol backbone on which one or two FAs, a phosphate group and amino alcohols are esterified, (3) sphingolipids composed of a ceramide backbone (made of a sphingoid base amidified with a FA) which can be further modified by glycosylation, phosphorylation, or addition of an inositol phosphate residue which can be glycosylated, (4) sterols constituted from a steroid backbone which can be modified by glycosylation and/or addition of a FA chain in the case of the sterylesters, glycosylesters, or acetylglycosylesters. The acyl chains of lipids can be hydroxylated and unsaturated to different degree and position resulting in even more diverse structures. The polar head grafted to the hydrophobic chains confers diverse polarity index to the molecular assembly. Hence, depending on the polarity of the mix of solvents used to extract lipids, some classes or species of lipids might be more efficiently extracted as compared to others, introducing a bias in their quantification. Some lipids such as the phosphorylated lipids, are more unstable than others, also skewing lipid quantification. Hence, using only one extraction method to quantify all lipids at once is not feasible. In the future, improved extraction and LC-MS methodologies will need to address these pitfalls to identify and compare the different lipid classes found in immunopurified compartments. LC-MS clearly has the potential to identify major and minor lipid species without potential biases from the separation and desorption of lipids from high-performance thin layer chromatography (HPTLC) plates.

For this purpose, performing a complete FA and sterol profile is a useful first-line of identification and characterization. Here, we describe the immunoisolation procedure used for lipid analyses. We also explain the procedure to perform a complete FA and sterol profiling of immunoisolated compartments, both at the preparative and analytical level.

128

129

130

131

132

133

134

135

136

137

138

139

140

141

142

143

144

145

146

147

148

149

150

151

152

153

154

155

156

157

158

159

160

161

Because this protocol is for immunoprecipitation of intact membrane compartments, the GFP tag has to be exposed to the cytosolic side of the membrane so that the anti-GFP antibody can bind to it. We recommend using transmembrane proteins (e.g., SNAREs [18] or V-ATPases [19]) as baits. However, some membrane associated proteins (e.g., RABs) work as well $[14,21]$. However, as $\mathrm{RAB}$ proteins can potentially dissociate from the membranes during purification and therefore not yield enough purified organelles, this protocol also describes and illustrates how to evaluate the efficiency of IP and validation of the extraction. The amount of 


\section{Author's Proof}

the plant material is one of the most crucial points of this experi- 173 ment. At least $10 \mathrm{~g}$ (fresh weight) of seedling materials should be 174 obtained for one IP. Seedlings can be collected from MS plates 175 $(12 \times 12 \mathrm{~cm})$ or from liquid culture. However, to reach $10 \mathrm{~g}$ of 176 fresh materials $200 \mu \mathrm{L}$ of seeds (120-160 mg of dry seeds) need to 177 be sowed. In this protocol we will describe a liquid culture method 178 allowing for easy production of fresh material in a relatively small 179 amount of time.

\subsection{Plant Material and Growth}

\subsection{Membrane Isolation and Protein Quantification}

1. Arabidopsis thaliana seeds expressing a GFP-tagged organelle 181 marker has been chosen as a bait. 182

2. Sterilization solution: $1 \%(\mathrm{w} / \mathrm{v})$ sodium dichloroisocyanurate 183 in sterile deionized water.

3. MS medium: $4.4 \mathrm{~g} / \mathrm{L}$ Murashige and Skoog medium including 185 vitamins, $10 \mathrm{~g} / \mathrm{L}$ sucrose, and $0.5 \mathrm{~g} / \mathrm{L} 2-(N$-morpholino $) 186$ ethanesulfonic acid (MES). Adjust the $\mathrm{pH}$ to 5.8 with $\mathrm{KOH} 187$ and autoclaved at $110^{\circ} \mathrm{C}$ for $30 \mathrm{~min}$. 188

4. $70 \%(\mathrm{v} / \mathrm{v})$ ethanol in $\mathrm{H} 2 \mathrm{O}$. 189

5. $500 \mathrm{~mL}$ baffled flasks. $\quad 190$ 191

1. $50 \mathrm{mM}$ HEPES in $\mathrm{H} 2 \mathrm{O}$. Adjust the $\mathrm{pH}$ to 7.5 with $\mathrm{KOH}$ and 192 keep at $4{ }^{\circ} \mathrm{C}$. 193

2. Vesicle isolation buffer: $0.45 \mathrm{M}$ sucrose, $5 \mathrm{mM} \mathrm{MgCl} 2,1 \mathrm{mM} 194$ dithiothreitol (DTT), and 0.5\% Polyvinylpyrrolidone (PVP, see 195 Note 1$)$ dissolved in $50 \mathrm{mM}$ HEPES pH 7.5. Store at $-20^{\circ} \mathrm{C} 196$ and keep at $4{ }^{\circ} \mathrm{C}$ for use. Just before use, add phenylmethyl- 197 sulfonyl fluoride (PMSF) at the final concentration of $1 \mathrm{mM} . \quad 198$

3. Wash buffer: $0.25 \mathrm{M}$ sucrose, $1.5 \mathrm{mM} \mathrm{MgCl2,} 0.2 \mathrm{mM}$ EDTA 199 $(\mathrm{pH} 8)$, and $150 \mathrm{mM} \mathrm{NaCl}$ dissolved in $50 \mathrm{mM}$ HEPES 200 $\mathrm{pH}$ 7.5. Store at $-20{ }^{\circ} \mathrm{C}$ and keep at $4{ }^{\circ} \mathrm{C}$ for use. 201

4. Resuspension buffer: $1 \mathrm{mM}$ PMSF and $1 \%(\mathrm{v} / \mathrm{v})$ protease 202 inhibitor cocktail in wash buffer. Prepare immediately before 203 use and keep at $4{ }^{\circ} \mathrm{C}$.

5. Sucrose solutions: 38\%, 33\%, and 8\% sucrose (w/v) in $50 \mathrm{mM} 205$ HEPES, pH 7.5.

6. Bicinchoninic Acid Protein Assay Kit. 207

7. Mortar (with the diameter about $20 \mathrm{~cm}$ ) and pestle. 208

8. Funnel. 209

9. Gauze or Miracloth (Millipore). 210

1. Anti-GFP, rabbit IgG, polyclonal (e.g., Thermo Fisher Scien- 212 tific, A-11122).

2. PBS-T: $150 \mathrm{mM} \mathrm{NaCl}, 2.7 \mathrm{mM} \mathrm{KCl}, 11.5 \mathrm{mM}$ Na2HP4, 214 $1.76 \mathrm{mM} \mathrm{KH} 2 \mathrm{PO} 4,0.02 \%(\mathrm{v} / \mathrm{v})$, Tween 20 . Keep at $4{ }^{\circ} \mathrm{C} . \quad 215$ 


\section{Author's Proof}

Yoko Ito et al.

\subsection{SDS-PAGE and Western Blotting}

2.5 Fatty Acid

Profiling (Fatty Acid

Methyl Esters: FAMEs)
3. Dynabeads Protein A for immunoprecipitation and magnetic 216 tube holder.

4. Bis[sulfosuccinimidyl]suberate $\left(\mathrm{BS}^{3}\right) . \quad 218$

5. $\mathrm{BS}^{3}$ conjugation buffer: $20 \mathrm{mM} \mathrm{Na} 2 \mathrm{HPO} 4,0.15 \mathrm{M} \mathrm{NaCl} .219$

6. $\mathrm{BS}^{3}$ working solution: $5 \mathrm{mM}$ in $\mathrm{BS}^{3}$ conjugation buffer. Pre- 220 $\begin{array}{ll}\text { pare before use. } & 221\end{array}$

7. $\mathrm{BS}^{3}$ quenching buffer: $1 \mathrm{M}$ Tris- $\mathrm{HCl} \mathrm{pH} 7.5$. 222

1. Primary antibodies: mouse anti-CFP/GFP/YFP for IP (e.g., 224 Roche 118144600001 at $1 / 1000)$; rabbit anti-SYP61 at 225 $1 / 1000$ [9] or, rabbit anti-ECHIDNA at 1/1000 [11] for 226 TGN detection; antibodies to detect contamination from 227 other compartments (e.g., rabbit anti-Membll at 1/1000 228 for Golgi [24], rabbit anti-V- ATPase-E [Agrisera, AS07 213] 229 at $1 / 2000$ for vacuole, rabbit anti-PMA2 at $1 / 1000$ for plasma 230 membrane [25], rabbit anti-PM-ATPase at 1/1000 for plasma 231 membrane [Agrisera, AS07 260]). 232

2. Secondary antibodies: goat anti-mouse IgG-HRP conjugate, 233 goat anti-rabbit IgG-HRP conjugate. 234

3. $5 \times$ loading buffer: $200 \mathrm{mM}$ Tris- $\mathrm{HCl}$ pH 6.8, 50\% (v/v) 235 glycerol, 5\% (w/v) sodium dodecyl sulfate (SDS), $250 \mathrm{mM} 236$ DTT, and $0.05 \%(\mathrm{w} / \mathrm{v})$ bromophenol blue. 237

4. $10 \%$ TGX Stain-Free FastCast Acrylamide Kit. 238

5. $N, N, N^{\prime}$-tetramethylethylenediamine (TEMED). 239

6. $10 \%(\mathrm{w} / \mathrm{v})$ ammonium peroxodisulfate (APS). 240

7. Running buffer: $25 \mathrm{mM}$ Tris- $\mathrm{HCl}, 192 \mathrm{mM}$ glycine, 241 $0.1 \%$ SDS. 242

8. SDS-PAGE molecular weight standards. 243

9. Transfer buffer: 25 mM Tris-HCl, $192 \mathrm{mM}$ glycine, $20 \%(\mathrm{v} / \mathrm{v}) \quad 244$ ethanol. 245

10. TBS-T: $20 \mathrm{mM}$ Tris-HCl, $140 \mathrm{mM} \mathrm{NaCl}, 2.5 \mathrm{mM} \mathrm{KCl}, 0.1 \% 246$ (v/v) Tween 20.

11. Blocking buffer: $5 \%(\mathrm{w} / \mathrm{v})$ nonfat dried milk in TBS-T. 248

12. Enhanced chemiluminescence (ECL) reagents. 249

13. Polyvinylidene difluoride (PVDF) membrane. 250

14. Blotting paper. 251

252

1. Hydrolysis solution: $5 \% \mathrm{H}_{2} \mathrm{SO}_{4}$ in methanol. 253

2. Hexane $99 \%$. 254

3. $2.5 \% \mathrm{NaCl}$ in $\mathrm{H}_{2} \mathrm{O}$. 255

4. $100 \mathrm{mM}$ Tris-HCl, $0.09 \% \mathrm{NaCl}, \mathrm{pH} 8$. 256

5. Distillated $\mathrm{H}_{2} \mathrm{O}$. 257 


\section{Author's Proof}

6. $100 \mathrm{mM}$ Tris-HCl. 258

7. BSTFA-TMCS $\mathrm{N}, \mathrm{O}$-bis(trimethylsilyl)trifluoroacetamide with 259 $1 \%$ trimethylchlorosilane. 260

2.6 Sterol Profiling

1. Ethanol.

2. $11 \mathrm{~N} \mathrm{KOH}$.

3. Hexane $99 \%$. 264

4. Distillated $\mathrm{H}_{2} \mathrm{O}$.

5. BSTFA-TMCS $\mathrm{N}, \mathrm{O}$-bis(trimethylsilyl)trifluoroacetamide with 266 $1 \%$ trimethylchlorosilane.

1. Heptadecanoic acid (17:0).

2. 2-hydroxytetradecanoic acid (h14:0).

3. Cholestan-2-ol (also known as $\alpha$-cholestanol). 271 Optional:

4. 1-Pentadecanol (OH-15:0).

5. 15-hydroxypentadecanoic acid ( $\omega \mathrm{OH}-15: 0)$.

1. Ice.

2. $50 \mathrm{~mL}$ Falcon tubes. 276

3. $10 \mathrm{~mL}$ and $25 \mathrm{~mL}$ disposable pipettes.

4. $1.5 \mathrm{~mL}$ microcentrifuge tubes. 279

5. $38 \mathrm{~mL}$ thin wall open-top ultracentrifugation tubes. 280

6. Glass Pasteur pipettes. 281

7. Screw glass tubes of $8 \mathrm{~mL}$. 282

8. Screw caps with Teflon seal. 283

2.9 Equipment $\quad$ 1. Shaker for flasks installed in plant incubator/growing facility. 285

2. $1.5 \mathrm{~mL}$ tube rotator. 286

3. Refrigerated centrifuge for centrifugation of $50 \mathrm{~mL}$ tubes in a 287 swinging-bucket rotor. $\quad 288$

4. Ultraspeed refrigerated centrifuge for centrifugation of $38 \mathrm{~mL} 289$ tubes in a swinging-bucket rotor at $150,000 \times g(r$ max $) . \quad 290$

5. Centrifuge for centrifugation of $8 \mathrm{~mL}$ glass tubes in a fixed- 291 angle bucket rotor. 292

6. Water bath. 293

7. Dry bath. 294

8. Spectrophotometer and cuvettes. 295

9. Protein electrophoresis device. 296

10. Power supply. 297 


\section{Author's Proof}

Yoko Ito et al.

2.10 Software

11. Stain-Free enabled imager (e.g., Bio-Rad ChemiDoc MP 298 imaging system).

12. Protein transfer device. 300

13. Air flow evaporator system for lipids. 301

14. GC-MS simple Quadrupole system equipped with an autosam- 302 pler, a mass detector, and a data processing station. An 303 HP-5MS capillary column (5\% phenyl-methyl-siloxane, $30 \mathrm{~m}, 304$ $250 \mathrm{~mm}$, and $0.25 \mathrm{~mm}$ film thickness; Agilent) is used in our 305 laboratory. $\quad 306$

1. MassHunter from Agilent.

2. NIST database. 309

3. Image J (https://imagej.net/Fiji). 310

3 Methods

\subsection{Growing Arabidopsis Seedlings in Liquid Culture}

1. Prepare one $1.5 \mathrm{~mL}$ tube for each culture flask (usually 4 tubes for 4 flasks for one IP), and place approximately $50 \mu \mathrm{L}$ of seeds (30-40 mg of seeds) per tube.

2. Sterilize the seed surface with $70 \%$ ethanol for $1 \mathrm{~min}$.

3. Remove the ethanol, add $1 \mathrm{~mL}$ of sterilization solution, and incubate for 20-30 min with continuous mixing in a tube rotator.

4. Wash 3-4 times with sterile distilled $\mathrm{H}_{2} \mathrm{O}$ ( see Note 2).

5. Keep seeds in the dark, at $4{ }^{\circ} \mathrm{C}$ for 2 days in sterile distilled $\mathrm{H}_{2} \mathrm{O}$.

6. Pour $250 \mathrm{~mL}$ of MS liquid medium into each $500 \mathrm{~mL}$ baffled flask and sterilize at $110{ }^{\circ} \mathrm{C}$ for $30 \mathrm{~min}$.

7. After the medium has cooled down at room temperature, place the seeds into each flask. Incubate for 8-9 days under $120 \mathrm{rpm}$ and long-day condition ( $16 \mathrm{~h}$ light $/ 8 \mathrm{~h}$ darkness) at $22{ }^{\circ} \mathrm{C}($ see Note 3).

To obtain intact membrane compartments with high purity, we 330 disrupt the seedlings in a detergent-free buffer, remove the debris, 331 and perform a two-step process including a sucrose cushion and a 332 sucrose step-gradient fractionation by ultracentrifugation. The 333 samples should be kept at $4{ }^{\circ} \mathrm{C}$ or on ice during all the manipula- 334 tions; precool buffers and tubes.

1. Precool the vesicle isolation buffer, $50 \mathrm{~mL}$ Falcon tubes (for 336 collecting the homogenate), mortar, and pestle in ice. Set the 337 swing-rotor centrifuge at $4{ }^{\circ} \mathrm{C}$. 338

2. Collect and weigh the seedlings (see Note 4). 339 
3. Transfer the seedlings into the mortar on ice, and grind them in 340 2-3 volumes (e.g., $20 \mathrm{~g}$ of seedlings in $60 \mathrm{~mL}$ ) vesicle isolation 341 buffer (see Note 5). 342

4. Set the funnel and gauze/Miracloth on the precooled $50 \mathrm{~mL} 343$ Falcon tube on ice. Harvest the homogenate with a disposable 344 pipette and filter it through the gauze/Miracloth. Squeeze the 345 waste to get as much material as possible. 346

5. Centrifuge the filtered homogenate at $1600 \times g$ for $20 \mathrm{~min}$ at 347 $4{ }^{\circ} \mathrm{C}$. Meanwhile, precool new $50 \mathrm{~mL}$ Falcon tubes in ice. $\quad 348$

6. Transfer the supernatant to the precooled $50 \mathrm{~mL}$ Falcon tubes 349 by decantation, and centrifuge at $1600 \times g$ for $15 \mathrm{~min}$ at $4^{\circ} \mathrm{C}$. 350 In total, step 5 should be performed 3-4 times. 351

7. Precool the $38 \%$ sucrose solution and $38 \mathrm{~mL}$ centrifuge tubes 352 in ice.

8. Transfer $8 \mathrm{~mL} 38 \%$ sucrose solution to $38 \mathrm{~mL}$ centrifuge tubes, 354 and load the last supernatant of step 6 on it (see Note 6, Fig. 1). 355 Ultracentrifuge at $150,000 \times g$ for $3 \mathrm{~h}$ at $4{ }^{\circ} \mathrm{C}$ with a swinging- 356 bucket rotor. Precool the $33 \%$ and $8 \%$ sucrose solutions in ice. 357

9. The membrane fraction appears at the interface between the 358 sucrose cushion and the supernatant as a yellow layer (Fig. 1). 359 Remove the supernatant using a $10 \mathrm{~mL}$ pipette (see Note 7). 360 On top of the membrane fraction, carefully load $15 \mathrm{~mL}$ of $33 \% 361$ sucrose solution, followed by $10 \mathrm{~mL}$ of $8 \%$ sucrose solution (see 362 Note 8, Fig. 1). 363

10. Ultracentrifuge at $150,000 \times g$ overnight $(16 \mathrm{~h})$ at $4{ }^{\circ} \mathrm{C} . \quad 364$

11. Precool $50 \mathrm{~mL}$ Falcon tubes and new $38 \mathrm{~mL}$ centrifuge tubes 365 in ice. Harvest separately the membrane fractions at the 38\%/ 366 $33 \%$ and $33 \% / 8 \%$ interfaces using a Pasteur pipette in pre- 367 cooled $50 \mathrm{~mL}$ Falcon tubes (see Note 9). 368

12. Dilute the collected membrane fractions into $1 / 3(\mathrm{v} / \mathrm{v})$ of 369 $50 \mathrm{mM}$ HEPES, pH 7.5. Mix gently by inverting the tubes. 370 Transfer it into the precooled $38 \mathrm{~mL}$ centrifuge tubes and 371 ultracentrifuge at $150,000 \times g$ for $3 \mathrm{~h}$ at $4{ }^{\circ} \mathrm{C}$. Meanwhile, 372 prepare resuspension buffer and keep it on ice.

13. Discard the supernatant by decantation. Wipe carefully the 374 inside of the centrifuge tubes with a paper towel without 375 touching the pellet. Resuspend the pellet (microsomal frac- 376 tion) with $0.5-1 \mathrm{~mL}$ resuspension buffer depending on the 377 size of the pellet. $\quad 378$

\subsection{Protein}

Quantification in the Total Membrane Fraction
If there are multiple microsomal fractions (e.g., when comparing 380 the membranes of drug-treated and nontreated plants or mutants 381 versus wild-type), the concentration of membrane material should 382 be equilibrated among samples. The membrane concentration is 383 assumed to be proportional to the protein concentration. We use 384 


\section{Author's Proof}

Yoko Ito et al.

a

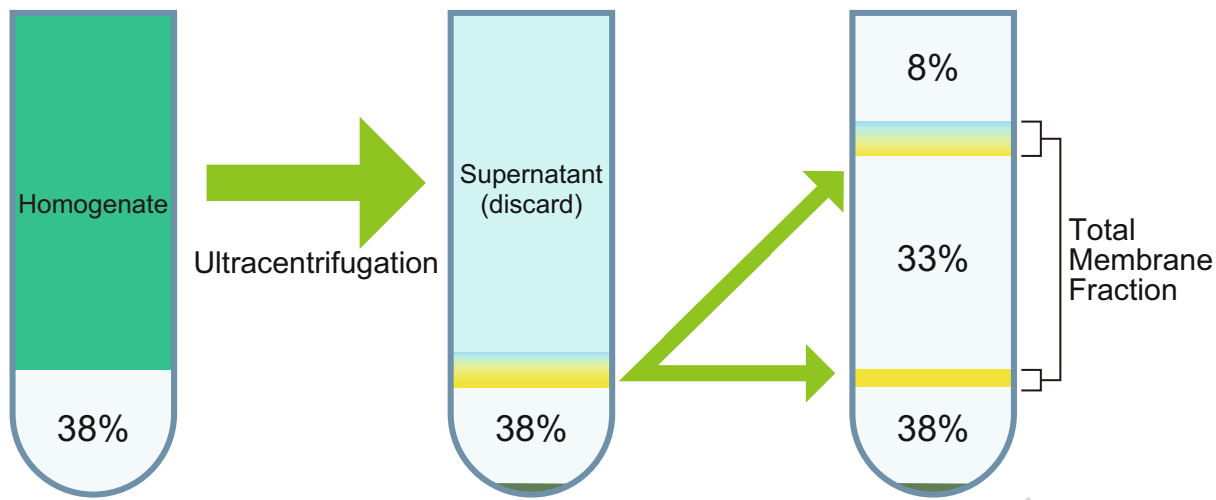

b

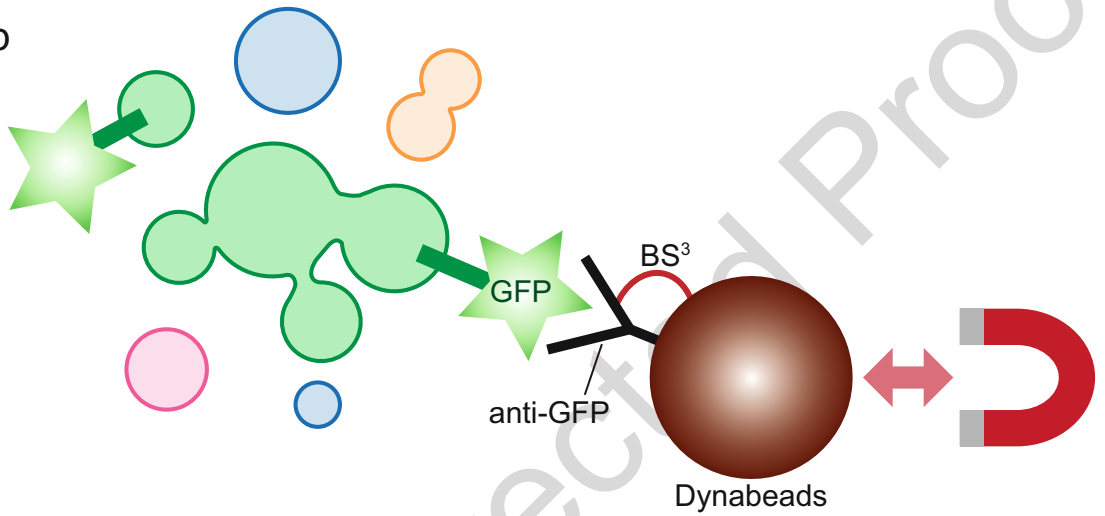

Fig. 1 Immunoprecipitation of intact endomembrane compartments. (a) Two-step membrane fractionation. Left: load the homogenate of Arabidopsis seedlings on a 38\% sucrose cushion and perform ultracentrifugation. Middle: After ultracentrifugation, the membrane fraction appears at the interface as a yellow layer. Discard the supernatant above the membrane fraction using a glass pipette. Right: By stepwise loading of $33 \%$ and $8 \%$ sucrose solutions, the membrane fraction is divided into two layers at the $8 \% / 33 \%$ and $33 \%$ / $38 \%$ interfaces. After an additional ultracentrifugation step, harvest those layers separately or together (see Note 9). (b) Schematic representation of membrane immunoprecipitation principle. Compartments which harbor the protein bait fused to GFP are recognized by the anti-GFP antibody. The antibody is conjugated to magnetic beads (Dynabeads) and cross-linked by BS $^{3}$. GFP-labeled compartments will be pulled down together with beads using magnetism

the bicinchoninic acid (BCA) protein assay kit to reliably quantify protein concentration and adjust samples accordingly.

1. Dilute $5 \mu \mathrm{L}$ of the microsomal fraction with $100 \mu \mathrm{L}$ of resuspension buffer (1/20 dilution). Prepare 2 tubes for each sample.

2. Measure the protein concentration of the diluted microsomal fractions using a BCA protein assay kit. Average the results of 
the 2 tubes for each sample and calculate the original concen- 392 tration (see Note 10). 393

3. Equilibrate the protein concentration of the microsomal frac- 394 tion with the resuspension buffer to the one with the lowest 395 concentration. 396

3.4 Immunoprecipitation

\subsection{Controls for IPS}

Conjugate the GFP antibody to Dynabeads by $\mathrm{BS}^{3}$, and immunoprecipitate the GFP-tagged compartments from the microsomal fraction. All the steps other than $\mathrm{BS}^{3}$ conjugation should be performed at $4{ }^{\circ} \mathrm{C}$ or on ice.

1. Prepare $150 \mu \mathrm{L}$ of Dynabeads in a $1.5 \mathrm{~mL}$ tube for each IP (see Note 11 ).

2. Wash the beads with cold $1 \mathrm{~mL}$ PBS-T by pipetting. Set the tubes on the magnetic tube holder, wait until the beads are pulled by the magnet, and remove the PBS-T.

3. Add $500 \mu \mathrm{L}$ PBS-T and cool the tubes on ice.

4. Add $15 \mu \mathrm{L}$ of anti-GFP and incubate for at least $1 \mathrm{~h}$ at $4{ }^{\circ} \mathrm{C}$ under continuous rotation by the tube rotator (see Note 12).

5. Remove the buffer containing the antibodies and wash the 410 beads with $500 \mathrm{~mL}$ of $\mathrm{BS}^{3}$ conjugation buffer (see Note 13).

6. Dissolve $\mathrm{BS}^{3}$ into $\mathrm{BS}^{3}$ conjugation buffer $\left(\mathrm{BS}^{3}\right.$ working solution, see Note 14).

7. Remove the buffer from the beads, and resuspend the beads with the $\mathrm{BS}^{3}$ working solution. Incubate for $30 \mathrm{~min}$ at room temperature with rotation.

8. Quench the reaction by adding $25 \mu \mathrm{L} B S^{3}$ quenching buffer. Incubate for $15 \mathrm{~min}$ at room temperature with rotation.

9. Transfer the tubes to ice. Wash the beads with $500 \mu \mathrm{L}$ of cold PBS-T three times.

10. Resuspend the beads with $500-1000 \mu \mathrm{L}$ of cold resuspension buffer, and cool them in ice for at least $10 \mathrm{~min}$.

11. Remove the buffer from the beads, and add $900 \mu \mathrm{L}$ of the equilibrated microsomal fraction from Subheading 3.2, step 13. Incubate for $\mathrm{l} \mathrm{h}$ at $4{ }^{\circ} \mathrm{C}$ with continuous rotation (see Note 15).

12. Remove the supernatant. Wash the beads with $1 \mathrm{~mL}$ of cold wash buffer four times, and finally resuspend in $70 \mu \mathrm{L}$ of wash buffer; this is the IP output fraction (see Note 16). Store at $-80{ }^{\circ} \mathrm{C}$ if you do not use the samples for further analysis in a short term.

To check the level of nonspecific background in immunoprecipitated samples, we advise to perform an IP from the microsomal fraction using beads without GFP antibody as negative control (skipping the steps Subheading 3.4, steps 4-10 for the preparation
397

398

399

400

401

402 403

404 405 406 407

408 409 410
411 412 413

414 415 416

417 418

419 420

421

422

423

424

425 


\section{Author's Proof}

Yoko Ito et al.

3.6 Enrichment and Purity Assessment of the IP Fraction of beads). An alternative negative control cab be obtained by doing an IP with GFP antibody-conjugated beads from a microsomal fraction extracted from wild-type plants that do not express any GFP-labeled protein bait.

The IP fraction should be checked by Western blotting to determine the enrichment level (the IP output fraction is compared with the microsomal IP input fraction) of the GFP-tagged compartment and contamination from other membranes. Primary antibodies appropriate for detection of SYP61 and other organelles are listed at Subheading 2.4, item 1 ( see Note 17).

We used the TGX Stain-Free system from Bio-Rad, which enables rapid visualization of proteins by the fluorescence of tryptophan excited by UV light, to quantify the total amount of proteins. If the system is not available, Coomassie brilliant blue (CBB) staining is the standard alternative.

1. Add $5 \mu \mathrm{L}$ of $5 \times$ loading buffer to $10 \mu \mathrm{L}$ of the IP output fraction or $5 \mu \mathrm{L}$ of the microsomal IP input fraction, adjust with $1 \times$ loading buffer to get a final volume of $25 \mu \mathrm{L}$ in every tube (see Note 18 ).

2. Perform electrophoresis using TGX Stain-Free 457 polyacrylamide gel.

3. Visualize the total protein profile using Stain-Free system 459 (Fig. 2). Using the Image J software, define equally sized

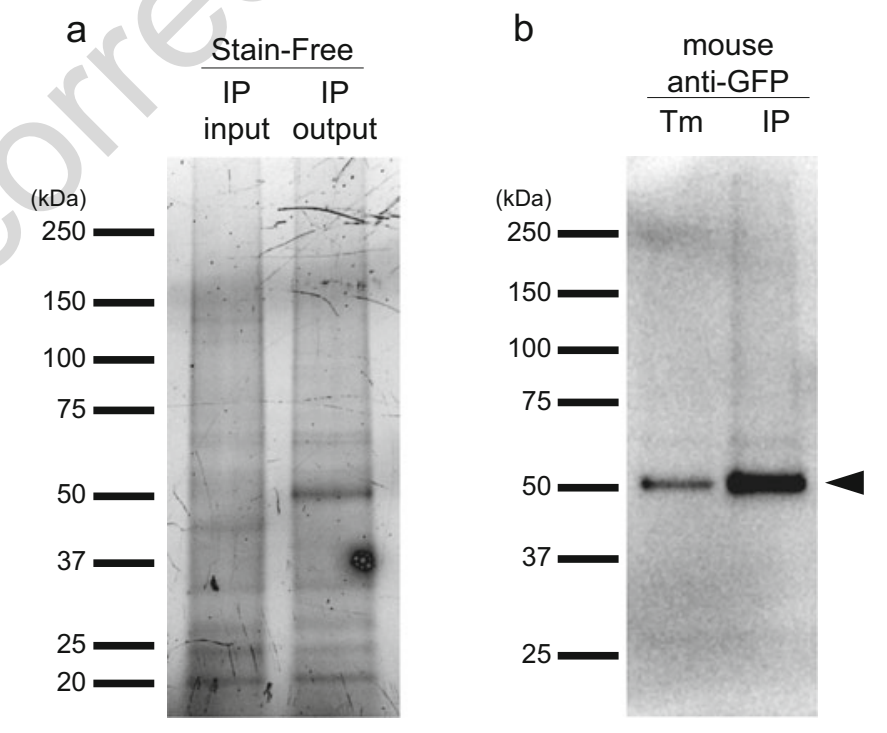

Fig. 2 Analysis of IP output fraction. (a) Stain-Free fluorescence image of a SDS-PAGE gel loaded with equal protein amounts of the IP input microsomal fraction (IP input) and IP output fraction (after beads incubation) using GFP-SYP61 as the IP bait. (b) Western blotting image displaying enrichment of TGN-SV in the IP output fraction as revealed by GFP-SYP61 detection by mouse anti-GFP antibody 


\section{Author's Proof}

boxes around each lane, analyze the signal intensity, and calcu- 461 late the ratio of the total protein amount between samples. 462 Dilute samples with $1 \times$ loading buffer to equalize the protein 463 concentration to that of the lowest one.

4. Perform a new SDS-PAGE of the equilibrated samples and 465 transfer the proteins to PVDF membranes using standard 466 protocols.

5. Perform immunoblotting using appropriate antibodies by stan- 468 dard protocols (Fig. 2). Use mouse anti-GFP antibodies to 469 know whether the bait has been pulled-down (Fig. 2). We 470 advise to use several other antibodies recognizing endogenous 471 proteins of the targeted compartments (like ECHIDNA for 472 SYP61/SVs-TGN) and antibodies against other organelle 473 marker proteins to check for potential contaminations from 474 other membranes. A list of appropriate antibodies is given in 475 Subheading 2.4, item 1 . 476

\subsection{Lipid Extraction}

\subsubsection{Total Fatty Acid} Extraction (Fatty Acid Methyl Esters: FAMEs)
In each experiment, a negative control should be prepared by 478 following the protocols described below replacing the IP output 479 fraction by IP wash buffer in step 1. In the negative control, only 480 the standards should be detected by GC-MS. 481

In addition, a vial containing $100 \mu \mathrm{L}$ of hexane should be 482 prepared as negative control for hexane contaminants. Use the 483 same hexane as used in Subheading 3.7, steps $\mathbf{I}$ and 2. No compo- 484 nents should be detected. In the case of contamination by plastics, 485 alkanes will be detected, in that case, use new hexane and proceed 486 with new lipid extraction.

1. Transfer $25-50 \mu \mathrm{L}$ of the IP output fraction in a screw glass 489 tube, named tube A (see Note 19). 490

2. Add $1 \mathrm{~mL}$ of the hydrolysis solution containing $5 \mu \mathrm{g} / \mathrm{mL}$ of 491 internal standard 17:0 and hl4:0 (see Note 20). 492

3. Incubate overnight at $85{ }^{\circ} \mathrm{C}$ in a dry bath, be sure that the 493 contents of tubes are not evaporating by retightening the screw 494 caps every 5-10 min during the first $30 \mathrm{~min}$. This step aims at 495 releasing the FAs of different lipid classes from their respective 496 backbone (Fig. 3, see Note 21).

4. Remove the tubes from the dry bath and let them cool down. 498

5. Add $1 \mathrm{~mL}$ of $2.5 \% \mathrm{NaCl}$ and then $1 \mathrm{~mL}$ of hexane. 499

6. Mix vigorously ( see Note 22). 500

7. Centrifuge for $5 \mathrm{~min}$ at $800 \times \mathfrak{g}$ at room temperature to 501 separate the phases.

8. Prepare new screw glass tubes containing $1 \mathrm{~mL}$ of $100 \mathrm{mM} 503$ Tris- $\mathrm{HCl}, 0.09 \% \mathrm{NaCl}, \mathrm{pH} 8$, named tube $\mathrm{B}$. 


\section{Author's Proof}

Yoko Ito et al.

A

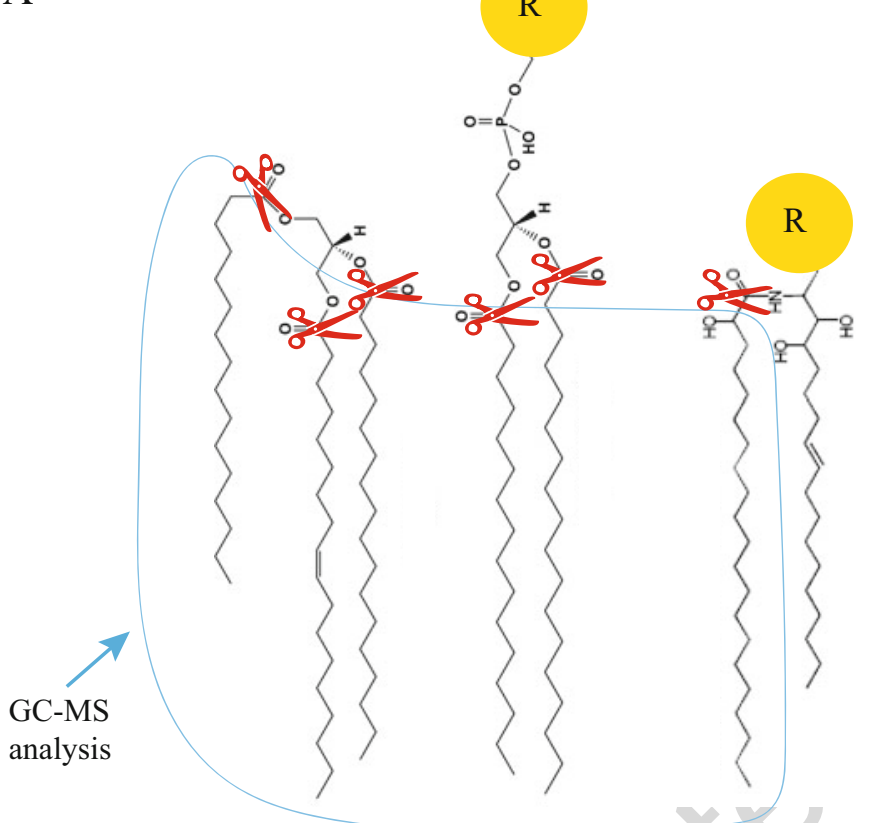

Glycerolipids Glycerophospholipids Sphingolipids
$\mathrm{B}$

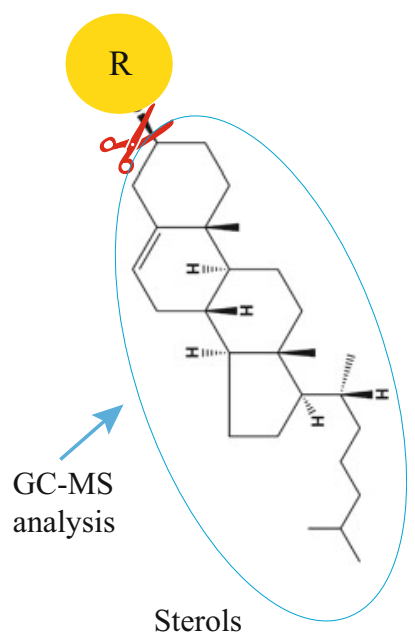

Fig. 3 Schematic representation of the hydrolysis of fatty acids (FAs) from the lipid backbone. (a) FAs esterified on the glycerol backbone in glycerolipids and glycerophospholipids or amidified on the long chain base of sphingolipids are cleaved through acidic hydrolysis (Methanol + sulfuric acid, see Subheading 3.7.1, step 2). (b) Basic hydrolysis (Ethanol $+\mathrm{KOH}$, see Subheading 3.7.2, step 2) cleaves esterified FAs chains grafted on a steroid backbone in the case of sterylesters, glycosylsterylesters, or acylated glycosylesters. Yellow circles are the radical groups esterified on glycerol backbone of glycerolipids and glycerophospholipids or esterified on the steroid backbone of sterols or amidified on the sphingoid backbone of sphingolipids; red scissors represent the cleavage of the ester or amid bonds; blue lines encircled the lipid part recovered after extraction and analyzed by GC-MS.

9. Collect the hexane upper phase (see Note 23) and transfer it to 505 the tube B prepared in previous step.

10. Add $1 \mathrm{~mL}$ of hexane to the initial tube A. 507

11. Mix vigorously. 508

12. Centrifuge for $5 \mathrm{~min}$ at $800 \times \mathfrak{g}$ at room temperature to 509 separate the phases.

13. Collect the hexane upper phase and add it to tube B. 511

14. Mix vigorously the content of tube $B$. 512

15. Centrifuge for $5 \mathrm{~min}$ at $800 \times \mathfrak{g}$ at room temperature to 513 separate the phases. 


\section{Author's Proof}

16. Recover gently the hexane upper phase taking care not to 515 contaminate the sample with the lower aqueous phase (see 516 Note 24) and transfer to a new glass tube. 517

17. Evaporate the hexane through air flow evaporator. 518

18. Add $200 \mathrm{~mL}$ of BSTFA. 519

19. Incubate for $15 \mathrm{~min}$ at $110^{\circ} \mathrm{C}$ in a dry bath. 520

20. Evaporate the BSTFA through air flux evaporator (see Note 521 25). 522

21. Once BSTFA is completely evaporated add $100 \mu \mathrm{L}$ of hexane 523 and close the lid immediately to avoid hexane evaporation. $\quad 524$

22. Vortex. 525

23. Transfer into GC vials containing a conical insert. 526

24. Run the sample in a GC-MS instrument using the FAMES 527 methods. 528

3.7.2 Sterol Extraction 1. Transfer $25-50 \mu \mathrm{L}$ of the IP output fraction in a screw 530 glass tube. 531

2. Add $1 \mathrm{~mL}$ of ethanol containing $5 \mu \mathrm{g} / \mathrm{mL}$ of cholestan-2-ol 532 and then $100 \mu \mathrm{L}$ of $11 \mathrm{~N} \mathrm{KOH}$; this is a saponification step 533 which eliminates FAs. Please note that this method will not 534 distinguish between sterols, sterylesters, sterylglycosides or 535 acetylated sterylglycosides in which a FA chain and/or a glu- 536 cose is grafted on a steroid backbone. 537

3. Incubate for $1 \mathrm{~h}$ at $80{ }^{\circ} \mathrm{C}$ in a dry bath. 538

4. Let cool the samples. 539

5. Add $1 \mathrm{~mL}$ of hexane. 540

6. Vortex. 541

7. Add $2 \mathrm{~mL}$ of distillated $\mathrm{H}_{2} \mathrm{O}$. 542

8. Mix vigorously. 543

9. Centrifuge for $5 \mathrm{~min}$ at $800 \times \mathfrak{g}$ at room temperature to 544 separate the phases. 545

10. Recover gently the hexane upper phase taking care not to 546 contaminate the sample with the lower aqueous phase (see 547 Note 24). 548

11. Evaporate the hexane through air flow evaporator. 549

12. Add $200 \mathrm{~mL}$ of BSTFA. 550

13. Incubate for $15 \mathrm{~min}$ at $110^{\circ} \mathrm{C}$ in a dry bath. 551

14. Evaporate the BSTFA through air flux evaporator. 552

15. Once BSTFA is completely evaporated add $100 \mu \mathrm{L}$ of hexane 553 ( see Note 26). 554

16. Vortex. 555 


\section{Author's Proof}

Yoko Ito et al.

\subsection{GC-MS Analysis}

\subsubsection{GC-MS Method}

\subsubsection{Identification} of Peaks

3.8.3 Calculation
17. Transfer into GC vials containing a conical insert.

18. Run the sample in GC-MS instrument using the sterol methods.

1. Set the helium carrier gas at $2 \mathrm{~mL} / \mathrm{min}$.

2. Use the splitless mode for injection.

3. Set the temperatures of injector to $250{ }^{\circ} \mathrm{C}$ and the auxiliary detector to $352{ }^{\circ} \mathrm{C}$.

4. Set the oven temperature to be held at $50{ }^{\circ} \mathrm{C}$ for $1 \mathrm{~min}$.

5. Program a $25{ }^{\circ} \mathrm{C} / \mathrm{min}$ ramp to $150{ }^{\circ} \mathrm{C}(2$-min hold) and a $10{ }^{\circ} \mathrm{C} / \mathrm{min}$ ramp to $320^{\circ} \mathrm{C}(6$-min hold $)$.

6. MS Analyzer is set in scan only with mass range $40-700 \mathrm{~m} / \mathrm{z}$ in positive mode with an electron emission set to $70 \mathrm{eV}$.

7. The temperature of MS Source is set to $230{ }^{\circ} \mathrm{C}$ and the MS Quad to $50{ }^{\circ} \mathrm{C}$.

Quantification of FAMES and sterols was based upon peak areas 572 that were derived from the total ion current. Each sample chro573 matogram is analyzed using the MassHunter software equipped with a NIST database. An automatic identification of the lipid species using algorithms developed by Agilent is recommended. However, manual integration could also be added to automatic integration results in order to consider lipids that are below the automatic threshold detection or lipids for which peaks would be too close to be separated by automatic detection (example in Fig. 4). An example of chromatogram resulting from a SYP61GFP IP output fraction is given in Fig. 4, see also Table 1. The retention times given in Fig. 4 are only indicative as these values change depending on the column and age of the column. The major FAs 16:0, 18:2, and 18:3 are typical for glycerolipids (DAG, TAG) and glycerophospholipids (phospholipids) while the $\alpha$-hydroxylated FAs (hFAs) are a specific feature of sphingolipids with h24:1 and h24:0 being enriched in SYP6l IP as described before [14]. Nonhydroxylated 24:0 FA is strongly present in the sphingolipid pool but could also be detected in the glycerophospholipid pool [14]. The fatty alcohols OH-18:0 and OH-20:0 as well as the dicarboxylic acid 18:2-DCA are typical from extracellular lipids such as cutin and suberin, which precursors are probably transported through the SYP61 compartment to reach the plasma membrane and be secreted in the apoplast.

The relative quantification is obtained by normalizing the peak area 597 of one lipid species to the appropriate internal standard area. Nonhydroxylated FAs, including dicarboxylic acids (DCAs), are normalized to 17:0; hFAs are normalized to h14:0. If other types of FAs, such as fatty alcohols or $\omega$-hydroxyFAs ( $\omega$-OH-FAs), are 


\section{Author's Proof}

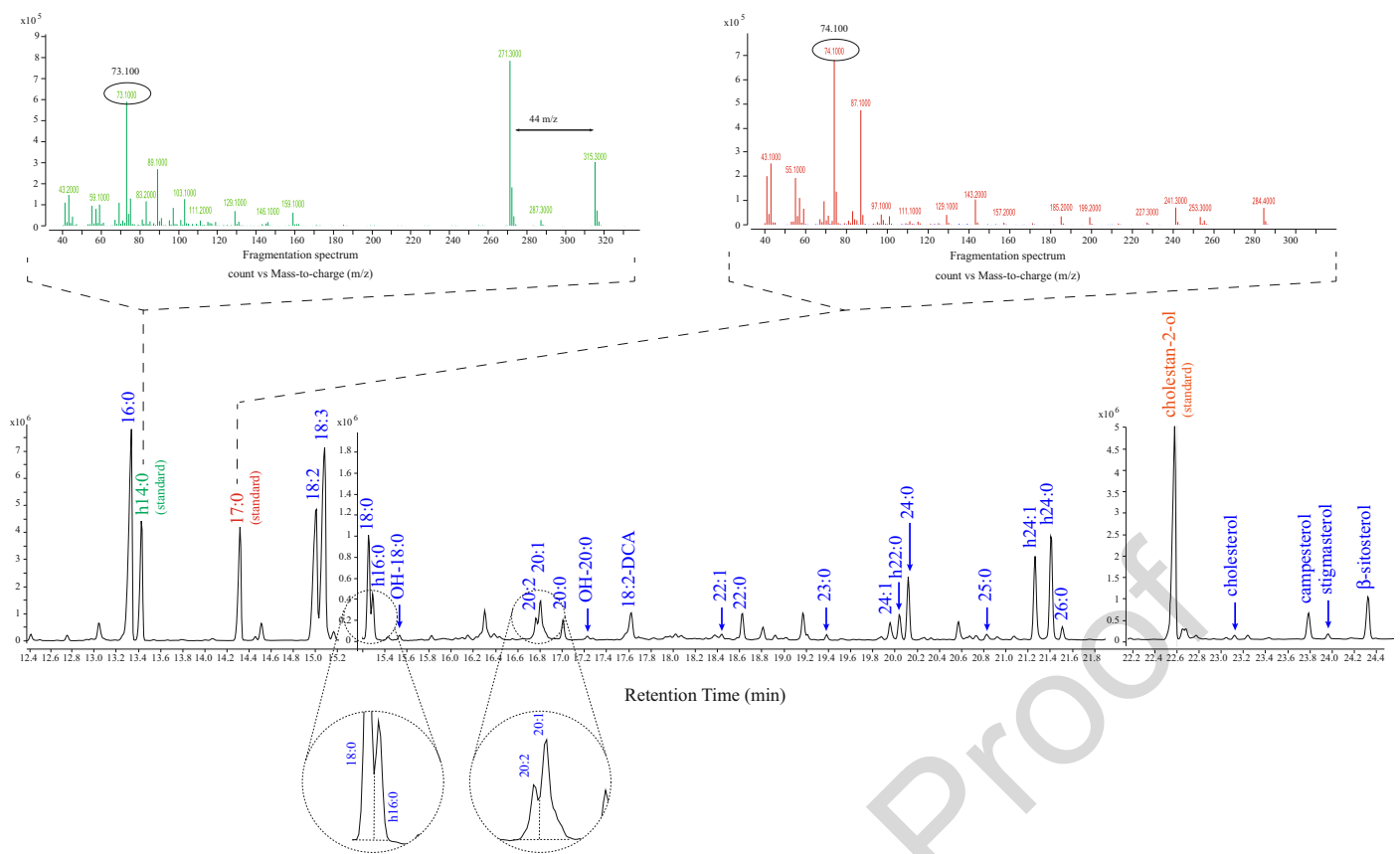

Fig. 4 Example of a typical FAMES and sterols chromatogram from a SYP61-GFP IP. Fragmentation spectrum of the $\alpha$-hydroxylated FA standard h14:0 is shown in green. The TMS group at $\mathrm{m} / \mathrm{z} 73.1$ and the $\mathrm{m} / \mathrm{z}$ 44 differences between the two major peaks are specific features of the $\alpha$-hydroxylated FAs. Fragmentation spectrum of the nonhydroxylated FA standard 17:0 is shown in red. The TMS group is at $\mathrm{m} / z 74.1$, which is typical of nonhydroxylated FA. All FAs are shown in blue. The dotted circles show two peaks close to one another for which manual integration could be helpful. All other peaks were automatically integrated

found, quantify them relatively to $\mathrm{OH}-15: 0$ (1-pentadecanol) or 602 $\omega$-OH-15:0 (15-hydroxypentadecanoic acid) standards, respec- 603 tively. These standards will need to be added at Subheading 3.7.1, 604 step 2 (see Note 20).

After normalization to the standard, the value obtained is 606 expressed in $\mu \mathrm{g}$ and then ng. This value could be further trans- 607 formed in nmol using the specific molecular weight of the 608 specific FA.

Different IP could yield different amount of material and thus 610 different lipids quantity (in $\mathrm{ng}$ or $\mathrm{nmol}$ ). We advise to always 611 perform IPs with the same protein concentration of microsomal 612 IP input fraction, and in the same volume. However, the yield of 613 the IPs could still be different. Hence, we do not advise to compare 614 directly the lipid quantity values (in ng or nmol) obtained from 615 different IPs. Instead, these values should be normalized. A classical 616 way is to normalize the lipid quantity values against the fresh or dry 617 weight of starting seedling material. This is, however, not possible 618 in this protocol as multiple steps of membrane fractionation are 619 performed prior to the IP, potentially leading to different amounts 620 of IP input material. Protein quantification of IP output fractions is 621 still possible but not reliable as antibodies used for IPs and possibly 622 


\section{Author's Proof}

Yoko lto et al.

t.1 Table 1

List of FAs typically found in SYP61 IP fraction

\begin{tabular}{|c|c|}
\hline FA short name & FA nomenclature name \\
\hline $16: 0$ & Hexadecanoic acid \\
\hline hl4:0 & 2-hydroxytetradecanoate \\
\hline $17: 0$ & Heptadecanoic acid \\
\hline $18: 2$ & Octadecadienoic acid \\
\hline $18: 3$ & Octadecatrienoic acid \\
\hline $18: 0$ & Octadecanoic acid \\
\hline hl6:0 & 2-hydroxyhexadecanoate \\
\hline $\mathrm{OH}-18: 0$ & 1-octadecanol \\
\hline $20: 2$ & Eicosadienoic acid \\
\hline $20: 1$ & Eicosenoic acid \\
\hline $20: 0$ & Eicosanoic acid \\
\hline OH-20:0 & 1-eicosanol \\
\hline 18:2-DCA & Octadecadiynoic acid \\
\hline $22: 1$ & Docosenoic acid \\
\hline $22: 0$ & Docosanoic acid \\
\hline $26: 1$ & Hexacosenoic acid \\
\hline $23: 0$ & Tricosanoic acid \\
\hline $24: 1$ & Tetracosenoic acid \\
\hline h22:0 & 2-hydroxydocosanoate \\
\hline $24: 0$ & Tetracosanoic acid \\
\hline $25: 0$ & Pentacosanoic acid \\
\hline h24:1 & 2-hydroxytetracosenoate \\
\hline h24:0 & 2-hydroxytetracosanoate \\
\hline $26: 0$ & Hexacosanoic acid \\
\hline h26:0 & 2-hydroxyhexacosanoate \\
\hline
\end{tabular}

the magnetic beads would interfere with most protein quantifica- 623 tion assays (see Note 18). Moreover, the protein-lipid ratio in membranes is clearly variable from one endomembrane compartment to another or from one experimental condition to another. Hence, using the protein-lipid ratio as a way of normalizing lipid quantities is clearly not the best approach. Instead, we suggest that, for IP samples, the quantity of one specific FA species should be normalized to the total amount of FAs found in the profile. The value will then be expressed as $\mathrm{ng} \%$ or $\mathrm{nmol} \%$. 


\section{Author's Proof}

1. There are multiple products with different molecular weight 634 for PVP. Use the one with the average molecular weight of 635 10,000 .

2. Because we use large amounts of seeds, the culture can easily be 637 contaminated with bacteria or fungi. Hence, seed sterilization 638 should be performed carefully.

3. For IPs of intact membrane compartments, it is always prefera- 640 ble to work with fresh material. We advise not to keep plant 641 material at $-80{ }^{\circ} \mathrm{C}$ before starting the membrane extraction, 642 fractionation, and IP.

4. Be careful not to let the seedlings dry during manipulation. 644 Fresh weight should be at least $10 \mathrm{~g}$, ideally 15-20 g.

5. It is easier to start grinding with a small volume of buffer (e.g., 646 $25 \mathrm{~mL}$ ), and add the rest during grinding. Because of the 647 toxicity of PMSF, the manipulation should be carried out 648 under a chemical fume hood.

6. Load the supernatant slowly and gently in order not to disrupt 650 the interface between the sucrose solution and the supernatant. 651 It is easier to load the first several milliliters with a P1000 652 pipetman. The thin wall open-top centrifuge tubes must be 653 filled up to $2-3 \mathrm{~mm}$ from the tube top to avoid deformation of 654 the tubes during ultracentrifugation. If the amount of the 655 supernatant is not enough to fill the tubes, add vesicle isolation 656 buffer.

7. When removing the supernatant, keep a thin layer of superna- 658 tant of approximately the same thickness of the yellow layer to 659 avoid pipetting membranes.

8. By loading $33 \%$ sucrose solution, the membrane fraction is 661 separated into two layers beneath and above the 33\% sucrose 662 solution. The upper fraction can accidentally get into the 663 pipette during this process. To avoid it, keep the sucrose solu- 664 tion continuously flowing out of the pipette while loading. The 665 loading of the two sucrose solutions should be performed 666 carefully; similar to the previous step, use a P1000 pipetman 667 to load the first several milliliters. Do not disrupt the interfaces. 668

9. Most of the small early endosomal compartments, TGN, and 669 Golgi will be located at the $33 \% / 8 \%$ interface, while an impor- 670 tant part of the late endosomal compartments will be located to 671 both $38 \% / 33 \%$ and $33 \% / 8 \%$ interfaces. Hence, it is advisable 672 to check beforehand by Western blot in which interface the 673 targeted compartment carrying the protein-GFP bait is most 674 enriched. In any case, it is alternatively possible to combine the 675 two fractions together. 


\section{Author's Proof}

Yoko Ito et al.

10. The protein concentration of the original microsomal fraction should be at least $1 \mathrm{mg} / \mathrm{mL}$, ideally around $2 \mathrm{mg} / \mathrm{mL}$. If the concentration is lower than $1 \mathrm{mg} / \mathrm{mL}$, we advise to start a new membrane extraction.

11. Before taking Dynabeads from the vial, resuspend the beads by vortex; beads sink to the bottom of the vial.

12. To thoroughly mix beads and antibodies, invert the tubes several times before setting the tubes on the rotator. The incubation can be overnight.

13. Collect the beads sticking on the lid of the tubes.

14. Prepare this solution freshly.

15. The incubation should neither be longer nor shorter than 1 h. 688

16. The IP output fraction contains the immunopurified membranes bound to the magnetic beads. As the beads sediment in the tube, homogenize by pipetting before using the IP output fraction for subsequent steps.

17. Because the IP is performed by using rabbit anti-GFP IgG, rabbit primary antibodies should not be used for the detection of GFP or proteins of similar molecular weight to IgG.

18. These amounts are suggested as a reference. Alternatively, protein quantification using a BCA protein assay could be performed. However, this method might be less reliable than visualizing the total protein profile on the TGX Stain-Free system due to (1) the presence of antibodies used for the IPs which create a bias in the protein quantification while they could easily be spotted on an SDS-PAGE, (2) the beads could

19. The beads are resistant to the hydrolysis solution and do not generate any molecules detectable by GC-MS.

20. The 17:0 standard is used to quantify the most common FAs coming from the glycerolipid and glycerophospholipid pool. The h14:0 standard is used to quantify the $\alpha$-hydroxylated (2-hydroxy)-FAs coming exclusively from the sphingolipid pool. Dicarboxylic acids (DCA) are FAs typical of the suberin and cutin lipids, which could be found in the FAs profile; quantification of DCA compounds is made with the 17:0 710 standard. Other types of FAs, such as fatty alcohols or $\omega$-hydroxyFAs, need to be quantified relative to OH-15:0 (1-pentadecanol) or $\omega$-OH-15:0 (15-hydroxypentadecanoic acid) standards, respectively; add $5 \mu \mathrm{g}$ of each in the hydrolysis solution.

21. Depending on the type of chemical bounds between FAs and the backbone, the hydrolysis will occur at different efficiency 


\section{Author's Proof}

esterified on the glycerol backbone while FAs of sphingolipids 721 are amidified on the sphingoid backbone, which is more diffi- 722 cult to hydrolyze than an ester bound. Hence, the overnight 723 incubation is necessary to correctly visualize the FAs coming 724 from the sphingolipid pool. Please note that FAs esterified on a 725 steroid backbone, such as in the case of sterylesters, glycosy- 726 lesters, or acetylglycosylesters, will also be hydrolyzed and thus 727 be part of the FAs pool detected in the profiling.

22. Shake tube for homogeneous mixing. Vortex only may not 729 result in efficient mixing.

23. Accidental collection of small amounts of the lower aqueous 731 phase does not matter at this stage, which is aimed at adjusting 732 the $\mathrm{pH}$ of the hexane phase.

24. Contrary to Subheading 3.7.1, step 9, it is important not to 734 collect any of the lower aqueous phase as this will interfere with 735 Subheading 3.7.1, step 18 resulting in misleading chromato- 736 gram results and may destroy the GC column. If some of the 737 aqueous phase was accidentally collected, a white residue com- 738 ing from the hydrolysis of trimethylsilyl (TMS) molecules that 739 release silicon atoms, will appear in Subheading 3.7.1, step 20. 740

25. If a white residue appears in the tube, add $\mathrm{l} \mathrm{mL}$ of hexane and 741 then $1 \mathrm{~mL}$ of $100 \mathrm{mM}$ Tris $-\mathrm{HCl}, 0.09 \% \mathrm{NaCl}, \mathrm{pH} 8$ and 742 resume at Subheading 3.7.1, step 14.

26. If a white residue appears in the tube, add $1 \mathrm{~mL}$ of hexane and 744 then $1 \mathrm{~mL}$ of distillated water and resume at Subheading 3.7.2, 745 step 8.

This work is supported by the French National Research agency 748 (ANR) grant "caLIPSO" to Y.B (ANR-18-CE13-0025). We grate- 749 fully acknowledge Laetitia Fouillen and Pierre Van Delft for helpful 750 discussions and support for lipidomic analyses (Plateforme 751 MetaboHUB-Bordeaux) (ANR-11-INBS-0010). The authors 752 would like to warmly acknowledge Natasha Raikhel (Distinguished 753 Professor of Plant Cell Biology, Institute for Integrative Genome 754 Biology, University of California Riverside, USA) for making avail- 755 able the SYP61-CFP Arabidopsis line and the support she originally 756 provided to analyze lipid content in immunopurified TGN fraction. 757 We thank Patrick Moreau and Sebastien Mongrand for helpful 758 comments and critical reading of the manuscript. 


\section{Author's Proof}

Yoko lto et al.

\section{References}

1. Dettmer J, Hong-Hermesdorf A, Stierhof YD, Schumacher K (2006) Vacuolar H+-ATPase activity is required for endocytic and secretory trafficking in Arabidopsis. Plant Cell 18 (3):715-730

2. Viotti C, Bubeck J, Stierhof YD, Krebs M, Langhans M, van den Berg W et al (2010) Endocytic and secretory traffic in Arabidopsis merge in the trans-Golgi network/early endosome, an independent and highly dynamic organelle. Plant Cell 22(4):1344-1357

3. Uemura T, Nakano RT, Takagi J, Wang Y, Kramer K, Finkemeier I et al (2019) A Golgireleased subpopulation of the trans-Golgi network mediates protein secretion in Arabidopsis. Plant Physiol 179(2):519-532

4. Uemura T, Suda Y, Ueda T, Nakano A (2014) Dynamic behavior of the trans-golgi network in root tissues of Arabidopsis revealed by superresolution live imaging. Plant Cell Physiol 55 (4):694-703

5. Donohoe BS, Kang BH, Staehelin LA (2007) Identification and characterization of COPIaand COPIb-type vesicle classes associated with plant and algal Golgi. Proc Natl Acad Sci U S A 104(1):163-168

6. Kang BH, Nielsen E, Preuss ML, Mastronarde D, Staehelin LA (2011) Electron tomography of RabA4b- and PI-4K $\beta 1$-labeled trans Golgi network compartments in Arabidopsis. Traffic 12(3):313-329

7. Ito $E$, Fujimoto $M$, Ebine $K$, Uemura $T$, Ueda T, Nakano A (2012) Dynamic behavior of clathrin in Arabidopsis thaliana unveiled by live imaging. Plant J 69(2):204-216

8. Brüx A, Liu TY, Krebs M, Stierhof YD, Lohmann JU, Miersch O et al (2008) Reduced V-ATPase activity in the trans-Golgi network causes oxylipin-dependent hypocotyl growth inhibition in Arabidopsis. Plant Cell 20 (4):1088-1100

9. Sanderfoot AA, Kovaleva V, Bassham DC, Raikhel NV (2001) Interactions between syntaxins identify at least five SNARE complexes within the Golgi/prevacuolar system of the Arabidopsis cell. Mol Biol Cell 12(12):3733-3743

10. Uemura $T$, Ueda $T$, Ohniwa RL, Nakano A, Takeyasu K, Sato MH (2004) Systematic analysis of SNARE molecules in Arabidopsis: dissection of the post-Golgi network in plant cells. Cell Struct Funct 29(2):49-65

11. Gendre D, Oh J, Boutté Y, Best JG et al (2011) Conserved Arabidopsis ECHIDNA protein mediates trans-Golgi-network trafficking and cell elongation. Proc Natl Acad Sci U S A 108 (19):8048-8053

12. Boutté Y, Jonsson K, McFarlane HE, Johnson E, Gendre D, Swarup R et al (2013) ECHIDNA-mediated post-Golgi trafficking of auxin carriers for differential cell elongation. Proc Natl Acad Sci U S A 110 (40):16259-16264

13. Chow CM, Neto H, Foucart C, Moore I (2008) Rab-A2 and Rab-A3 GTPases define a trans-golgi endosomal membrane domain in Arabidopsis that contributes substantially to the cell plate. Plant Cell 20(1):101-123

14. Wattelet-Boyer V, Brocard L, Jonsson K, Esnay N, Joubès J, Domergue F et al (2016) Enrichment of hydroxylated C24- and C26-acyl-chain sphingolipids mediates PIN2 apical sorting at trans-Golgi network subdomains. Nat Commun 7:12788

15. Dunkley TP, Watson R, Griffin JL, Dupree P, Lilley KS (2004) Localization of organelle proteins by isotope tagging (LOPIT). Mol Cell Proteomics 3(11):1128-1134

16. Parsons HT, Christiansen K, Knierim B, Carroll A, Ito J, Batth TS et al (2012) Isolation and proteomic characterization of the Arabidopsis Golgi defines functional and novel components involved in plant cell wall biosynthesis. Plant Physiol 159(1):12-26

17. Parsons HT, Stevens TJ, McFarlane HE, VidalMelgosa S, Griss J, Lawrence N et al (2019) Separating Golgi proteins from cis to trans reveals underlying properties of cisternal localization. Plant Cell 31(9):2010-2034

18. Drakakaki G, van de Ven W, Pan S, Miao Y, Wang J, Keinath NF et al (2012) Isolation and proteomic analysis of the SYP61 compartment reveal its role in exocytic trafficking in Arabidopsis. Cell Res 22(2):413-424

19. Groen AJ, Sancho-Andrés G, Breckels LM, Gatto L, Aniento F, Lilley KS (2014) Identification of trans-golgi network proteins in Arabidopsis thaliana root tissue. J Proteome Res $13(2): 763-776$

20. Geldner N, Dénervaud-Tendon V, Hyman DL, Mayer U, Stierhof YD, Chory J (2009) Rapid, combinatorial analysis of membrane compartments in intact plants with a multicolor marker set. Plant J 59(1):169-178

21. Heard W, Sklenár J, Tomé DF, Robatzek S, Jones AM (2015) Identification of regulatory and cargo proteins of endosomal and secretory 


\section{Author's Proof}

869 pathways in Arabidopsis thaliana by proteomic 870 dissection. Mol Cell Proteomics 14 $871 \quad(7): 1796-1813$

872 22. Wallroth A, Haucke V (2018) Phosphoinosi873 tide conversion in endocytosis and the endoly874 sosomal system. J Biol Chem 293 $875 \quad(5): 1526-1535$

876 23. Yang JS, Gad H, Lee SY, Mironov A, Zhang L, 877 Beznoussenko GV et al (2008) A role for phos878 phatidic acid in COPI vesicle fission yields 879 insights into Golgi maintenance. Nat Cell Biol $880 \quad 10(10): 1146-1153$
24. Marais C, Wattelet-Boyer V, Bouyssou G, Hocquellet A, Dupuy JW, Batailler B et al (2015) The Qb-SNARE Membll interacts specifically with Arfl in the Golgi apparatus of Arabidopsis thaliana. J Exp Bot 66 (21):6665-6678

25. Morsomme P, Dambly S, Maudoux O, Boutry $M$ (1998) Single point mutations distributed in 10 soluble and membrane regions of the Nicotiana plumbaginifolia plasma membrane PMA2 $\mathrm{H}+$-ATPase activate the enzyme and modify the structure of the C-terminal region. J Biol Chem 273(52):34837-34842 


\section{Author Queries}

Chapter No.: 11 475777_2_En

Chapter No.: 11 475777_2_En

\begin{tabular}{|l|l|l|}
\hline Query Refs. & Details Required & Author's response \\
\hline AU1 & $\begin{array}{l}\text { Please check whether the author names and } \\
\text { affiliations are correct. }\end{array}$ & $\begin{array}{l}\text { Please check whether the presentation of "Table } \\
1 \text { " is okay as typeset. }\end{array}$ \\
\hline AU2
\end{tabular}

\section{Author's Proof}

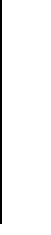

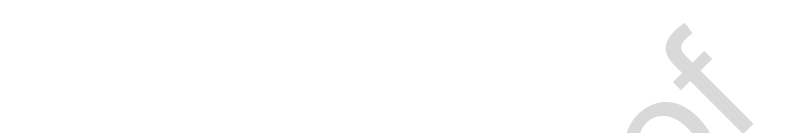

.

is okay as typeset. 